\title{
Sociometric Status and Social Drinking: Observations of Modelling and Persuasion in Young Adult Peer Groups
}

\author{
Sander M. Bot • Rutger C. M. E. Engels • \\ Ronald A. Knibbe • Wim H. J. Meeus
}

Received: 12 July 2006 / Accepted: 24 April 2007 / Published online: 21 June 2007

(C) Springer Science + Business Media, LLC 2007

\begin{abstract}
Because young adult drinking occurs primarily in peer groups, this should be taken into account when studying influences on drinking behaviour. This paper aimed to assess influences on drinking by observing existing peer groups in a naturalistic setting. We first analysed the basic levels at which two types of influence take place. The first, modelling (imitating others' drinking), was found to significantly influence individual drinking, whereas for the second one, persuasion (drinking resulting from others offering drinks), no predictions were found. Subsequently, we examined whether peer group members' sociometric status in the group affected the amount of influence and persuasion exerted and received. No indications were found that sociometric status had an impact on influence in alcohol consumption within a drinking situation. Features and weaknesses of the study are discussed.
\end{abstract}

Keywords Peer influence - Alcohol consumption ·

Sociometric status · Observations

S. M. Bot $(\varangle) \cdot$ R. C. M. E. Engels

Behavioural Science Institute, Radboud University Nijmegen, Nijmegen, The Netherlands

e-mail: s.bot@pwo.ru.nl

\section{R. A. Knibbe}

Medical Sociology, Maastricht University,

Maastricht, The Netherlands

\section{W. H. J. Meeus}

Department of Child and Adolescent Studies, Utrecht University, Utrecht, The Netherlands

\section{Introduction}

Peers are assumed to have an important impact on young persons' drinking levels (see review by Petraitis et al. 1995). Traditionally, best friends are the main focus when studying peer influences (e.g., Andrews et al. 2002; Jaccard et al. 2005; Poelen et al. 2007). The drinking behaviour of best friends may be a useful parameter in measuring peer influence, since best friends spend much time together (Jost et al. 1985) and play an important role in the lives of young adults (Hartup 1996). On the other hand, because young adult drinking in The Netherlands is concentrated in social settings such as bars, discos and pubs (Engels et al. 1999) and takes place primarily in groups (Van de Goor 1990), it is likely to assume that peer group members besides the best friend influence individual alcohol consumption (see e.g. also the Social Impact Theory; Latané 1981). Moreover, it is questionable whether the emotional bond that exists between best friends necessarily implies that they exert the strongest influence on individual drinking.

We acknowledge that the best friend may be influential concerning, for instance, the frequency of visiting places in which alcohol is consumed (Engels et al. 1999; Fink and Wild 1994). However, within a drinking situation, often more people are involved in shaping the actual drinking of a person, and a friendship between two people may not be the most important aspect affecting the magnitude of influence. For instance, Bot et al. (2005b) showed that nonreciprocal friends may have more influence on drinking than reciprocal ones, which may indicate that in a dyad not consisting of typical best friends, the influence may be stronger than in a reciprocal friendship. Further, findings as to whether the best friend or peer group members exert more influence on adolescent alcohol consumption are 
inconsistent (Bauman and Ennett 1996; Ennett and Bauman 1996; Maxwell 2001; and Urberg et al. 1997). Therefore, we postulate that peer influence may depend on factors other than friendship, and that the influence of others within a specific drinking situation is neglected in most studies (see also Cairns et al. 1998). In studies in which the influence of peers other than friends has been examined, the unit of analysis is often substance use of the group members in general (for an overview: Bauman and Ennett 1996), and not separate group members. The aim of the present study is to examine the role of peer group members' sociometric status in the prediction of influence on individual drinking.

Many researchers - starting with Moreno (1934) suggested that the power to influence others depends on an individual's sociometric position in the group. The information individuals provide regarding which group members they, for example, like and dislike, perceive to be popular, or perceive to be withdrawn, appears to be related to a variety of characteristics, such as leadership, aggression, athletic skills, and power to control or influence others (e.g., Lease et al. 2002a). In terms of alcohol consumption, one might expect that the more dominant and popular group members exert a stronger influence on the drinking levels of other group members, whereas more withdrawn and permissive members are more susceptible to be affected by peer group drinking. As far as we know, very few studies examined the role of sociometric position in the actual influence on others in the group (Polansky et al. 1950a, b). In studies the objective is usually the perception of (power to) influence others or susceptibility to influence (as reported in questionnaires by peers, teachers or parents) and not the actual interpersonal influence (Lease et al. 2002a; b). Even though the outcomes of these studies may be a good indicator of actual social influence being exerted, it is uncertain to what extent and on which time scale this influence occurs. In this study we explore whether information on the sociometric status of individuals in a peer group determines actual influence on the drinking levels of individual members.

In most studies that apply sociometric measurements the focus is on groups that are formed in a top-down manner, such as school classes and work groups. Alcohol consumption, however, is a behaviour that typically takes place in friendship groups, which are formed in a bottom-up manner. The composition and development of friendship groups might e.g. depend on the group members' opinion about the others and the individual decision to stay or leave the group (Engels et al. 1997). Even though composed groups, for which it is more common to apply sociometric measurements, are fundamentally different from friendship groups, we assume that the application of sociometric measurements is also meaningful in friendship groups, or possibly even more meaningful. Reasons may be that individuals are more motivated to remain a member of a friendship group, or because emotional wellbeing depends more on friendship groups compared with, for instance, professional groups (Van Daalen et al. 2005). Even though memberships of friendship groups are on a voluntary basis, differences in intrapersonal preferences, or even antipathies, may occur commonly. Further, the impact resulting from one's position in a peer group may be larger than in a composed group, because in friendship groups behaviour is not often defined by rules made by others (e.g. teachers), but merely by implicit and explicit rules imposed by the group members themselves. Also, in the case of social drinking, in which the amount of alcohol consumed is often not planned ahead but situation dependent (Knibbe et al. 1991), individuals may be more sensitive to peer influence. In sum, we assume that sociometric information may be a useful parameter in predicting influence concerning drinking in peer groups.

It is often reported that peer influence takes place in diverse ways (Cialdini and Sagarin 2005; Graham et al. 1991) and this should therefore be incorporated in our research design. Within a drinking situation, both modelling and persuasion have been found to account for unique variance in alcohol use according to survey studies (Aitken 1985; Brown et al. 1986; Graham et al. 1991; Keefe 1994). Modelling (also referred to as passive pressure) refers to adapting drinking levels to the consumption of other persons. Persuasion (also referred to as active pressure) refers to soliciting others to engage in a certain drinking behaviour. The relative impact that passive and active pressure have may be modified by an individual's position in the group, as reflected by the sociometric status. The role of sociometric status on these two processes of peer influence may be twofold. On the one hand, peer group members with a certain sociometric status (e.g. those who are more popular or dominant) may be more influential than others, by being both a behavioural model and by persuading others. On the other hand, a certain sociometric status (e.g. being perceived as conformist or socially anxious) may be related to a higher susceptibility to influence, both by means of modelling others or by being persuaded to drink. In conclusion, we will test whether sociometric measures differentiate which individuals may be more likely to be modelled by others in the group, or will be more likely to persuade others to drink. Also, it will be tested whether sociometric status differentiates between which individuals may be more likely to model others or be affected by others who persuade them to drink. ${ }^{1}$

\footnotetext{
${ }^{1}$ For more information on refusal assertiveness, see Epstein et al. (2001).
} 
In the present study, we test the impact of sociometric status of peer group members on peer influence processes on alcohol consumption. In contrast to researchers who employed a longitudinal survey design to study peer influence processes, we examine influence in existing peer groups in a bar lab, as we think it is essential to capture these processes in its natural context (see Bruun 1959). Modelling and persuasion, namely, are assumed to occur on several occasions during a "wet" situation, to take place partly unconsciously (Chartrand and Jefferis 2003), and incidents of conceding to social influence may be uncomfortable to admit; all of these may lead to bias in self reports. We think that only in a naturalistic context it is possible to assess the actual process in which influence takes place during drinking sessions.

\section{Materials and Methods}

\section{Participants}

The participants were 238 young adults who volunteered to participate (see also Bot et al. 2005a). They entered our laboratory setting as a group in a sense that one undergraduate student invited six to eight friends to join this research project. A total of 30 peer groups enrolled. The majority of the groups $(n=27)$ consisted of eight persons; two groups consisted of seven, and one of nine persons. A total of 128 men (54\%) and 110 women (46\%) participated in age range $18-28$ years, ${ }^{2}$ of whom $203(85 \%)$ had at least finished education allowing admittance to university, which indicates that this study involved participants with a relatively high educational level. A total of 50 respondents $(21 \%)$ lived with their parents or other caretakers, whereas the remainder either lived alone or with a partner or friend. The vast majority of the participants were from Dutch nationality and of Caucasian origin, but we also had some North African and Central Asian participants. The composition of the groups ranged from all men $(7 \%)$ through a variety of mixed gender $(86 \%)$ to all women $(7 \%)$.

\section{Procedure}

The participants were approached on the campus grounds and invited to join a study on the effects of alcohol on group discussions and judgements. This explanation was offered to avoid drawing the participants' attention to the

\footnotetext{
$\overline{{ }^{2} \text { Drinking in }}$ public in The Netherlands is allowed from 16 years on.
}

actual aims of the study, i.e. examining alcohol consumption in an ad-lib drinking setting. This type of procedure is employed in many studies on modelling effects of alcohol consumption (see review by Quigley and Collins 1999). The groups were invited to our bar lab for two sessions in 1 year; this article presents the results of the first measurement only. The sessions lasted $2 \mathrm{~h}$ each and took place between 7 and 9 P.M. in a bar laboratory on our campus. This bar lab was situated in a room furnished as an ordinary small pub, with a bar and stools, tables and chairs, indoor games (e.g. table soccer and billiards), and a TV/video set. During the sessions the radio played popular music. Volume and type of music were kept similar for all groups. Participants were told that we rented this bar from the faculty and that it was normally used for private parties and celebrations of staff members of the university.

First, after the participants had entered the bar lab, the procedure of the study was explained. Then, they were asked to fill in a questionnaire containing various questions about e.g. drinking patterns, friendships, and sociometric status within the group. This took about $40 \mathrm{~min}$. Next, they evaluated ten persons for attractiveness and intelligence by means of images shown on the TV screen, after which they had $30 \mathrm{~s}$ to discuss each image within the group. This task was constructed to be undemanding, since answers were dependent on the participants' own judgement. The aim of employing an undemanding task was to avoid that the amount of alcohol consumed was dependent on some participants' urges to do well. During the completion of the questionnaire and task non-alcoholic drinks were offered.

After completing the first task, which took about $10 \mathrm{~min}$, they had a 52 min break, in which they had to stay in the bar lab. They could play some of the games, watch TV, or have conversations. Participants were told that they could order a drink at the bar, but that the bartender would not offer them anything because this would burden him unnecessarily, and it would be unethical for researchers to push the participants towards drinking. This way we could assume that the drinking resulted only from the respondents' initiation. Soft alcoholic beverages (i.e. beer and wine) and non-alcoholic drinks were freely available. It is essential to mention that soft alcoholic drinks are relatively cheap in The Netherlands; for example, in ordinary bars or restaurants the price of a 0.251 beer does not exceed 2 Euros. This implies that offering drinks for free does not encourage excess drinking for the majority of Dutch youngsters (compare for instance the drinking levels reported by Van de Goor 1990). Of course, if this study had been conducted in countries with a different drinking culture, offering drinks for free might lead to binge drinking in some of the participants. Nonetheless, many students consumed a substantial number of drinks in this time-out session. Nuts and chips were also offered for free. After the 
52 min free time slot, a second task similar to the first one, but with different pictures had to be carried out. After $2 \mathrm{~h}$ the participants went home by taxi. They received 30 Euros per group for their participation.

During the 2-h session video and audio recordings were made. Two cameras were used (one flexible with zoom, and one steady), unobtrusively placed in two corners of the bar lab. A research assistant operated the camera in an observation room adjacent to the bar lab. Participants were told in advance that they would be observed during the complete experiment and all gave written permission for the use of these data for our study. We stressed that they were not obliged to drink alcohol, because non-drinkers or light drinkers were also of interest for our study. Pilot studies were conducted to verify the credibility of the setting and procedure (see Bot et al. 2005b). Participants strongly endorsed the setting's credibility and none of the 32 participants in the pilot studies guessed the actual aim of the study. Participants were allowed to smoke during the session (if the other group members approved), because in the pilot studies we noticed that forcing smokers not to smoke while drinking strongly affects the feasibility of a normal drinking occasion for them.

The research proposal was approved and funded by The Netherlands Organisation for Scientific Research. The local medical ethical committee (CCMO Arnhem-Nijmegen) approved of the protocols for our study. Debriefing was done after the second assessment. After debriefing, the participants were reminded of the possibility to withdraw their consent to use the observational data in our research or ask additional questions. None of them withdrew consent.
Measures

Sociometric Status in the Peer Group Sociometric nominations of peer group status are a powerful method to assess individual group positions relevant to the study of social influence, among other reasons, because they are multiinformant. Nevertheless, few attempts have been made to assess sociometric status in young adult leisure groups. We applied the nomination method described by Newcomb and Bukowski (1983) ("Which three persons in the group do you like most/least") to assess social impact (a sum of like and dislike nominations received) and preference (a subtraction of like and dislike nominations received) (items 1 and 2, see Table 1), and combined this with 12 items to assess six more constructs we regarded potentially relevant in terms of social influence (both in terms of influence exerted or received), which are all displayed in Table 1. Some of these items arose from a consideration of the Revised Class Play (Masten et al. 1985), but were adapted to fit the assessment sociometric status of young adults in a friendship group. The constructs other than impact and preference were labelled "social" (items 3 and 4), "leadership" (items 5 and 6), "withdrawal" (7 and 8), "dominance" (9 and 10), "confidence" (11 and 12), and "conformism" (13 and 14) and were offered in randomised order. In concordance with the method applied by Newcomb and Bukowski, all items asked for the names of three persons in the group for whom the statement applied most. The nominations the respondents gave were transformed into the probability of being nominated (the number of nominations received divided by the maximum possible

Table 1 Items and pattern matrix of the sociometric peer group nomination scale

\begin{tabular}{|c|c|c|c|}
\hline Item & $\begin{array}{l}\text { Dimension } 1 \\
\text { Social-Leader }\end{array}$ & $\begin{array}{l}\text { Dimension } 2 \\
\text { Conformism }\end{array}$ & $\begin{array}{l}\text { Dimension } 3 \\
\text { Impact }\end{array}$ \\
\hline 1. Social Impact & & & 0.762 \\
\hline 2. Social Preference & 0.792 & 0.306 & 0.101 \\
\hline \multicolumn{4}{|l|}{ Which 3 persons in the group... } \\
\hline 3. ...are easygoing and cooperative? & 0.818 & & \\
\hline 4. ...are open and spontaneous? & 0.810 & & -0.161 \\
\hline 5. ... are able to motivate others? & 0.671 & -0.379 & 0.219 \\
\hline 6. ...facilitate cooperation? & 0.834 & & \\
\hline 7. ....are surly and introverted? & -0.670 & 0.265 & 0.374 \\
\hline 8. ...are shy and withdrawn? & -0.523 & 0.449 & 0.300 \\
\hline 9. ...dominate the conversation? & 0.566 & -0.457 & 0.100 \\
\hline $10 .$. like to be in charge in the group? & 0.511 & -0.541 & 0.133 \\
\hline 11. ...have a lot of self-confidence? & 0.223 & -0.702 & 0.224 \\
\hline 12. ...don't lose their heads? & 0.140 & -0.694 & 0.394 \\
\hline 13. ...find it hard to say no? & 0.360 & 0.781 & \\
\hline 14. ...tend to conform to group norms? & & 0.759 & 0.165 \\
\hline
\end{tabular}

$N=214$. Values under 0.100 are suppressed; values over 0.500 are printed in bold. 
Fig. 1 Eigenvalues of the sociometric peer group nomination scale dimension
Scree Plot

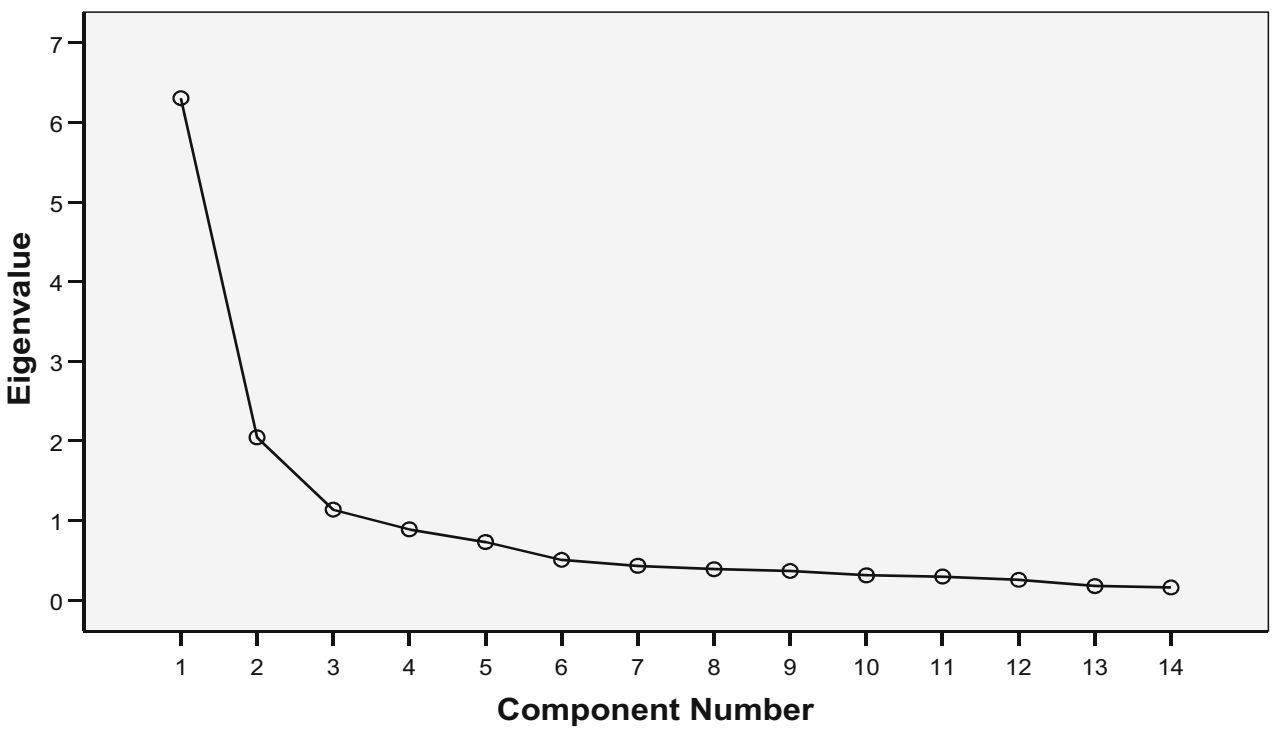

nominations one could obtain in the group), by the software program 'SOCSTAT' (Thissen-Pennings and Bendermacher 2002). We allowed both same-gender and cross-gender nominations.

Since this instrument was newly developed, we tested the structure of our constructs by conducting a principal components analysis (see scree plot in Fig. 1). Direct oblique rotation was applied to approximate underlying constructs rather than searching for uncorrelated sociometric dimensions. Three interpretable sociometric dimensions with Eigenvalues of $6.31,2.05$, and 1.14 (following the Kaiser criterion) were found, accounting for $67.77 \%$ of the total variance. The pattern matrix is depicted in Table 1 . In concordance with the first sociometric dimension revealed in the revised class play, the first sociometric dimension found in our study could be labelled Sociability-Leadership (45.04\% of the variance; Cronbach's Alpha: 0.91). Preference, sociability, leadership, dominance and withdrawal (negative) all loaded high on this sociometric dimension. The second sociometric dimension was labelled Conformism (14.61\% of the variance; Cronbach's Alpha: 0.81), with the conformism items loading highly positive, and the confidence items loading highly negative. The third sociometric dimension mainly consisted of the score on impact ( $8.13 \%$ of the variance). Individual scores on the sociometric dimensions were calculated by multiplying the individual probability scores on each construct with the item's loading on the sociometric dimensions and adding up the scores on all constructs. ${ }^{3}$ Dividing by the sum of the

\footnotetext{
${ }^{3}$ In case of negative loadings on a sociometric, the original scores on the items were reversed and multiplied with the positive value of the loading.
}

loadings provided individual scores on the sociometric dimensions.

Weekly Alcohol Consumption Weekly alcohol consumption was assessed by asking on which of the previous seven days the respondent consumed alcohol and, if so, how many drinks were consumed. The summed amount of drinks of the last 7 days was used in the analyses (cf. Hajema and Knibbe 1998).

Observed Alcohol Consumption We counted the number of drinks consumed in the 52-min break during the ad-lib drinking session using The Observer 5.0 (Noldus Information Technology b.v., Wageningen, The Netherlands). In the present study we used beer glasses that were smaller than standard glasses. In all sessions the same glasses were used, and filled to the same level. The contents of beer glasses were on average $160 \mathrm{ml}$ and the contents of wine glasses $110 \mathrm{ml}$ (a standard glass). The (lager) beer used in our study contained 5\% alcohol, which means that a glass of beer contained on average $8 \mathrm{ml}$ pure alcohol. The wines we offered contained from 11 to $12 \%$ alcohol, therefore a glass of wine contained from 12.1 to $13.2 \mathrm{ml}$ pure alcohol. Assuming that participants drank more glasses of beer since the glasses were smaller, we divided the number of glasses consumed beer by 1.5 to end up with a score reflecting standard drinks. If participants did not finish their drinks at the end of the session, we subtracted the remaining volume from the total consumption. Non-alcoholic drinks were not counted for this measure. Several research assistants scored the amount of drinks participants consumed and offered; the intraclass correlation was 0.90 . This relatively high level of agreement, together with an analysis of the recordings in which different codings appeared, and a 
discussion about the differences between the observers' initial codings, led us to decide to allow drinking to be coded by one observer.

Alcoholic Consumptions Offered The number of times an offer was made to each group member for an alcoholic consumption was counted.

\section{Strategy for Analyses}

To explore the relations between the variables tested in this study, we first calculated Pearson correlations. To examine to what extent respondents' drinking was influenced by other group members, we tested the impact of modelling and persuasion from others in the peer group. Because modelling and persuasion only occur within groups, and participants' observed drinking levels are strongly dependent on the specific peer group they are in, (reflected in the intraclass correlation; $r=0.46, p<0.001$ ), we used multilevel analyses (MLwiN 2.02) to answer our questions. We tested both fixed and random effects; fixed effects are the regression weights of the independent variables, and random effects indicate the variance in the regression weights between groups. If a random effect is found, this means that a relation between an independent and dependent variable varies between groups.

Individuals have a certain habitual drinking pattern which predicts individual drinking in our bar lab (Bot et al. 2005b), and we assumed that the drinking behaviours and persuasive actions of others might lead to individual drinking outcomes other than predicted by drinking habits. We tested this by applying the actor-partner interdependence model, as proposed by Kenny et al. (2002). In this model, outcome behaviour is predicted by an actor and a partner effect. The individual effect is called the actor effect. The effect from the group members, called the partner effect, is composed by summarising the individual scores of all group members other than the individual. In our analyses, we used the habitual drinking pattern of each individual, as reflected in the weekly alcohol consumption given in the questionnaire, as actor effect. The mean of the others' weekly alcohol consumption was used as partner effect. This way the impact of others in the group on individual behaviour, corrected for the individual's initial behaviour, can be calculated. By correcting for initial behaviour we aim to capture changes in drinking, rather than absolute drinking levels; this way we assume to reflect influence processes. To test whether any of the three sociometric dimensions had an effect on the amount of influence exerted, we calculated three other partner effects, in which the other group members' mean weekly consumption was weighed by their scores on the three sociometric dimensions we found. The effects of both the original partner effect and the three partner effects based on sociometric status were tested to observe whether any of the three sociometric dimensions resulted in a significantly better prediction of individual alcohol consumption.

Then, we tested whether scores on any of the three sociometric dimensions influenced the extent to which respondents were susceptible to modelling the drinking of others. This was done by calculating and testing interactions of the (standard) partner effect with individuals' scores on the sociometric dimensions. A significant interaction would indicate that the score on a sociometric dimension has an effect on the magnitude of the partner effect.

It is conceivable that applying other group members' drinking scores originating from the questionnaires may not be a powerful enough measure to find partner effects on an individual's alcohol consumption. The relation between weekly drinking (as assessed in the questionnaire) and observed drinking in the bar lab is moderate $(r(214)=$ $0.342, p<0.001)$, and intrapersonal differences between peer group drinking according to the questionnaire and according to observations may distort findings concerning modelling. Therefore, we also conducted analyses in which we applied the observed drinking of group members as partner effect in the prediction of individual drinking. A problem with this analysis is that the assumption of independence in the data is violated. A group member's drinking is a dependent variable, but also part of the partner effect of the other group members. Strictly speaking, one can state that associations are being tested in this analysis, instead of influence. Nevertheless, it can be informative to observe whether stronger associations exist with the drinking of individuals with a certain score on the sociometric status dimensions, than with individuals with different scores.

In the same series of analyses, we tested the effect of persuasion on individual drinking. The effect of offers for alcoholic consumptions on individual drinking was tested. Again, we tested whether interactions existed between the sociometric status of the one offering drinks and the individual reported consumption of the one being offered drinks on observed drinking, and between the sociometric status of the one being offered drinks and his or her reported alcohol consumption on observed drinking.

Concerning the analyses of the observational data, we had to omit two groups; one because of technical problems, and one because the group members decided to do a drinking game during the time-out session. In the latter group, individual drinking behaviour could of course not be predicted by possible explanatory variables such as the chosen activity. It should be stressed that none of the other 28 groups played drinking games. 


\section{Results}

\section{Descriptive Statistics}

A total of 122 males (57\%) and 92 females (43\%) were involved in the 28 groups we analysed. Group composition ranged from all males through all females to mixed gender groups, and participants were aged $18-28$ years $(M=20.48$; $\mathrm{SD}=2.10$ ). For age, no differences were found concerning alcohol consumption and amount of influence received or exerted, so age was left out of the subsequent analyses. On average, participants drank $16.83(\mathrm{SD}=14.55)$ alcoholic drinks in the last week (the mean for Dutch students is 16 a week; Maalsté 2000), and 2.77 ( $S D=1.44)$ standard alcoholic drinks in our research setting. The average number of alcoholic consumptions offered to group members during the break was $1.07(\mathrm{SD}=2.85)$.

Associations Between Sociometric Dimensions and Drinking Variables

Table 2 presents the correlations between the model variables. Sociability-Leadership (sociometric dimension 1) and Conformism (sociometric dimension 2) are negatively moderately correlated, whereas between sociometric dimension 1 and 3 (positive) and between sociometric dimension 2 and 3 (negative) small correlations exist. The three sociometric dimensions were not significantly related to reported and observed alcohol consumption and offers for drinks. Males reported higher weekly drinking levels in the questionnaire and drank more in the observed setting, but no significant gender differences existed concerning the amounts of offers for alcoholic drinks given as well as received. Weekly alcohol consumption is positively related to observed drinking and offering and being offered alcoholic drinks, but observed drinking is unrelated to offering and being offered alcohol. This could be an indication that offering drinks leads to convergence of drinking in a setting. Finally, offering drinks and being offered drinks are slightly positively related.

Multilevel Analyses on Modelling and Persuasion of Observed Drinking

Table 3 presents the results of four multilevel analyses. The first shows that, overall, gender plays an important role in determining the amounts of alcohol consumed in the bar lab setting. Further, the reported weekly alcohol consumption is a positive predictor of observed alcohol consumption (Actor-effect), and the reported drinking of peer group members is another marginally significant predictor (at the 0.10-significance level) of individual drinking. Random effects were found for the intercept, gender, and their covariance, indicating that the overall drinking levels differed per group, as did the effect of gender, which varied between groups and depended on the overall drinking level. The three other analyses in Table 3, in which the partner effects were weighted for individual scores on the sociometric dimensions, showed a similar picture and no smaller model deviance as compared to that in the overall analysis, indicating that adjusting group members' reported alcohol consumption for sociometric status in the partner effect does not lead to a better prediction of modelling than without weighing for individual scores on the sociometric dimensions. For sociometric dimension 1 (social-leader), which would intuitively be the most interesting sociometric dimension when searching for a strong predictor of social

Table 2 Correlations between model variables

\begin{tabular}{|c|c|c|c|c|c|c|c|}
\hline & $\begin{array}{l}\text { Dimension } \\
1 \\
\text { Social- } \\
\text { Leader }\end{array}$ & $\begin{array}{l}\text { Dimension } \\
2 \\
\text { Conformism }\end{array}$ & $\begin{array}{l}\text { Dimension } \\
3 \\
\text { Impact }\end{array}$ & Gender & $\begin{array}{l}\text { Weekly } \\
\text { consumption }\end{array}$ & $\begin{array}{l}\text { Observed } \\
\text { consumption }\end{array}$ & $\begin{array}{l}\text { Offering } \\
\text { alcohol }\end{array}$ \\
\hline \multicolumn{8}{|l|}{ Social Leader } \\
\hline Conformism & $-0.695^{* *}$ & & & & & & \\
\hline Impact & $0.152^{*}$ & $-0.267 * *$ & & & & & \\
\hline Gender & -0.014 & 0.126 & -0.101 & & & & \\
\hline $\begin{array}{l}\text { Weekly } \\
\text { consumption }\end{array}$ & 0.063 & -0.114 & 0.017 & $-0.362 * *$ & & & \\
\hline $\begin{array}{l}\text { Observed } \\
\text { consumption }\end{array}$ & 0.090 & -0.107 & 0.021 & $-0.446^{* *}$ & $0.342 * *$ & & \\
\hline Offering alcohol & 0.123 & -0.114 & -0.016 & -0.100 & $0.183^{* *}$ & 0.125 & \\
\hline $\begin{array}{l}\text { Being offered } \\
\text { alcohol }\end{array}$ & 0.067 & -0.080 & 0.061 & -0.105 & $0.238^{* *}$ & 0.118 & $0.189 * *$ \\
\hline
\end{tabular}

$N=214 .{ }^{* *} p<0.001 ;{ }^{*} p<0.01$ 
Table 3 Multilevel analyses on differences regarding influence from reported drinking on observed drinking behaviour

\begin{tabular}{|c|c|c|c|c|}
\hline & Overall Values (SE) & Social-Leader Values (SE) & Conformism Values (SE) & Impact Values (SE) \\
\hline \multicolumn{5}{|l|}{ Fixed Effects } \\
\hline Intercept & $3,01(0.50)^{*}$ & $3.16(0.49)^{*}$ & $3.07(0.49)^{*}$ & $3.03(0.49)^{*}$ \\
\hline Gender & $0.75(0.21)^{*}$ & $0.74(0.20)^{*}$ & $0.76(0.21)^{*}$ & $0.75(0.21)$ \\
\hline Actor (Weekly) & $0.02(0.01)^{* *}$ & $0.02(0.01)^{* *}$ & $0.02(0.01)^{* *}$ & $0.02(0.01)^{* *}$ \\
\hline Partner (Weekly) & $0.03(0.01)^{* * *}$ & - & $0.01(0.00)^{* * *}$ & $0.01(0.00)^{* * *}$ \\
\hline Gender X Actor (Weekly) & - & - & - & - \\
\hline Gender X Partner (Weekly) & - & - & - & - \\
\hline \multicolumn{5}{|l|}{ Random Effects } \\
\hline \multicolumn{5}{|l|}{ Level 2} \\
\hline Intercept & $2.81(1.15)$ & $2.77(1.14)$ & $2.78(1.14)$ & $2.82(1.15)$ \\
\hline Gender & $0.45(0.28)$ & $0.41(0.28)$ & $0.43(0.28)$ & $0.45(0.29)$ \\
\hline Actor (Weekly) & - & - & - & - \\
\hline Partner (Weekly) & - & - & - & - \\
\hline Gender X Actor (Weekly) & - & - & - & - \\
\hline Gender X Partner (Weekly) & - & - & - & - \\
\hline Covariance Intercept-Gender & $-1.13(0.56)$ & $-1.08(0.55)$ & $-1.11(0.55)$ & $-1.14(0.56)$ \\
\hline \multicolumn{5}{|l|}{ Level 1} \\
\hline Intercept & $0.91(0.10)$ & $0.91(0.10)$ & $0.91(0.10)$ & $0.91(0.10)$ \\
\hline \multicolumn{5}{|l|}{ Deviance intercept-only model: 677.78} \\
\hline Deviance full model & 631.43 & 633.23 & 631.82 & 631.41 \\
\hline$\chi^{2}$ (as compared to empty model) & 46.35 & 44.55 & 45.96 & 46.37 \\
\hline
\end{tabular}

$N=214 .{ }^{*} p<0.001 ; * * p<0.01 ; * * * p<0.10$. Presented values are significant, or obligatory (when non-significant, indicated with NS) model variables. Non-significant values are omitted from the analyses, and indicated by dashes.

influence, the partner effect was not even marginally significant, indicating that the reported drinking of the individuals scoring highest on sociability and leadership was not predictive of other participants' observed drinking.
Table 4 shows whether differences between members exist concerning susceptibility for peer group influence. The overall test is equal to the one in Table 3 , but now interactions were tested of the participant's sociometric

Table 4 Multilevel analyses on differences regarding susceptibility to influence from reported drinking on observed drinking behaviour

\begin{tabular}{|c|c|c|c|c|}
\hline & Overall Values (SE) & Social-Leader Values (SE) & Conformism Values (SE) & Impact Values (SE) \\
\hline \multicolumn{5}{|l|}{ Fixed Effects } \\
\hline Intercept & $3,01(0.50)^{*}$ & $3.01(0.50)^{*}$ & $3.01(0.50)^{*}$ & $3.01(0.50)^{*}$ \\
\hline Gender & $0.75(0.21)^{*}$ & $0.75(0.21)^{*}$ & $0.75(0.21)^{*}$ & $0.75(0.21)^{*}$ \\
\hline Actor (Weekly) & $0.02(0.01)^{* *}$ & $0.02(0.01)^{* *}$ & $0.02(0.01)^{* *}$ & $0.02(0.01)^{* *}$ \\
\hline Partner (Weekly) & $0.03(0.01)^{* * *}$ & $0.03(0.01)^{* * *}$ & $0.03(0.01)^{* * *}$ & $0.03(0.00)^{* * *}$ \\
\hline Dimension & $\mathrm{X}$ & - & - & - \\
\hline Dimension X Partner & $\mathrm{X}$ & - & - & - \\
\hline \multicolumn{5}{|l|}{ Random Effects } \\
\hline \multicolumn{5}{|l|}{ Level 2} \\
\hline Intercept & $2.81(1.15)$ & $2.81(1.15)$ & $2.81(1.15)$ & $2.81(1.15)$ \\
\hline Gender & $0.45(0.28)$ & $0.45(0.28)$ & $0.45(0.28)$ & $0.45(0.28)$ \\
\hline Actor (Weekly) & - & - & - & - \\
\hline Partner (Weekly) & - & - & - & - \\
\hline Dimension & - & - & - & - \\
\hline Dimension X Partner & - & - & - & - \\
\hline Covariance Intercept-Gender & $-1.13(0.56)$ & $-1.13(0.56)$ & $-1.13(0.56)$ & $-1.13(0.56)$ \\
\hline \multicolumn{5}{|l|}{ Level 1} \\
\hline Intercept & $0.91(0.10)$ & $0.91(0.10)$ & $0.91(0.10)$ & $0.91(0.10)$ \\
\hline \multicolumn{5}{|l|}{ Deviance intercept-only model: 677.78} \\
\hline Deviance full model & 631.43 & 631.43 & 631.43 & 631.43 \\
\hline$\chi^{2}$ (as compared to empty model) & 46.35 & 46.35 & 46.35 & 46.35 \\
\hline
\end{tabular}

$N=214 . * p<0.001 ; * * p<0.01 ; * * * p<0.10$. Presented values are significant, or obligatory (when non-significant, indicated with NS) model variables. Non-significant values are omitted from the analyses, and indicated by dashes. Variables not in the analysis are indicated with an X. 
dimension score with the partner effect. A significant interaction would indicate that individuals with a high score on the sociometric dimension would more likely be affected by the reported drinking of others in the group. Intuitively sociometric dimension 2 , on which the "confidence" and "conformism" items scored high, would be most likely to affect susceptibility to modelling others' drinking. Nevertheless, no interactions were found, and thus we can state that sociometric status does not affect susceptibility to modelling.

Table 5 shows the results of the multilevel analyses in which observed drinking of the group members was taken as a predictor of individual drinking levels. Main gender, actor and partner effects were found, but were specified by interactions between gender and actor effect, and gender and partner effect. Corrected for these interactions the main effects for gender and actor effect disappeared and only the partner effect remained significant. This implies that the drinking behaviour of others in the group was predictive of both male and female drinking. The interaction of gender and actor effect means that, only for girls, the reported drinking in the last week was predictive of drinking in the bar setting. The interaction of gender and partner effect entails that drinking of group members in the setting was more predictive concerning drinking in men. Apparently, males are more sensitive to the drinking behaviour of others in shaping their own drinking rate (see also Engels et al. 2006). Weighing the partner effect with each of the three sociometric dimensions and conducting the same analyses led to slightly better, but not significantly better results (for sociometric dimension 2 and 3 ) in the prediction of individual drinking, implying that no stronger associations exist with the drinking of participants who were scoring high on any of the sociometric dimensions. Furthermore, we tested in this model whether offering alcoholic drinks had an effect on drinking. It was found that being offered drinks had no effect on drinking, nor had weighing for the sociometric dimension score of the persons who offered drinks. Finally, gender of the one being offered alcoholic consumptions made no difference in observed drinking.

Table 6 shows that scores on the sociometric dimensions were also unrelated to the extent to which group members' drinking was associated with others' drinking.

\section{Discussion}

The aim of this study was to examine the role of peer group members' sociometric status on influence exerted and received concerning alcohol consumption in a naturalistic setting. Other group members' reported and actual drinking levels predict individual drinking. Reported drinking accounts for a small but significant part of other group members' drinking, which means that young people's drinking habits actually influence others' drinking in a peer group setting. Within the setting individual drinking strongly predicts others' drinking, so it can be concluded that strong similarities exist in drinking within the situation, which can be partly explained by reported individual drinking. This supports the argument that peers are important in shaping the drinking of individuals into adulthood (see also Bartholew et al. 2003), at least when together in a drinking setting. It is noteworthy that robust evidence was found for modelling but not for persuasion.

Table 5 Multilevel analyses on differences regarding influence from others' observed drinking on individual observed drinking behaviour

\begin{tabular}{|c|c|c|c|c|}
\hline & Overall Values (SE) & Social-Leader Values (SE) & Conformism Values (SE) & Impact Values (SE) \\
\hline \multicolumn{5}{|l|}{ Fixed Effects } \\
\hline Intercept & $0.13(0.62) \mathrm{NS}$ & $0.18(0.63) \mathrm{NS}$ & $0.42(0.60) \mathrm{NS}$ & $0.11(0.61) \mathrm{NS}$ \\
\hline Gender & $0.34(0.42) \mathrm{NS}$ & $0.38(0.42) \mathrm{NS}$ & $0.22(0.42) \mathrm{NS}$ & $0.39(0.41) \mathrm{NS}$ \\
\hline Actor (Weekly) & $-0.01(0.02) \mathrm{NS}$ & $-0.02(0.02) \mathrm{NS}$ & $-0.02(0.02) \mathrm{NS}$ & $-0.02(0.02) \mathrm{NS}$ \\
\hline Partner (Observed) & $1.35(0.20)^{*}$ & $2.48(0,37)^{*}$ & $2.53(0.39)^{*}$ & $2.40(0.34)^{*}$ \\
\hline Being offered & - & - & - & - \\
\hline Gender X Actor (Weekly) & $0.02(0,01)^{* * *}$ & $0.02(0,01)^{* * *}$ & $0.02(0,01)^{* * *}$ & $0.02(0,01)^{* * *}$ \\
\hline Gender X Partner (Observed) & $-0.48(0,15)^{*}$ & $-0.94(0,27)^{*}$ & $-0.90(0,30)^{*}$ & $-0.89(0,25)^{*}$ \\
\hline Gender X Being offered & - & - & - & - \\
\hline \multicolumn{5}{|l|}{ Random Effects } \\
\hline \multicolumn{5}{|l|}{ Level 1} \\
\hline Intercept & $0.98(0.10)$ & $1.04(0.10)$ & $0.98(0.10)$ & $1.05(0.10)$ \\
\hline \multicolumn{5}{|l|}{ Deviance intercept-only model 677.78} \\
\hline Deviance full model & 603.33 & 615.47 & 602.81 & 602.73 \\
\hline$\chi^{2}$ (as compared to empty model) & 74.45 & 62.31 & 74.97 & 75.05 \\
\hline
\end{tabular}

$N=214 . * p<0.001 ; * * p<0.01 ; * * * p<0.10$. Presented values are significant, or obliged (when non-significant, indicated with NS) model variables. Non-significant values are omitted from the analyses, and indicated by dashes. 
Table 6 Multilevel analyses on differences regarding susceptibility to influence from others' observed drinking on individual observed drinking behaviour

\begin{tabular}{|c|c|c|c|c|}
\hline & Overall Values (SE) & Social-Leader Values (SE) & Conformism Values (SE) & Impact Values (SE) \\
\hline \multicolumn{5}{|l|}{ Fixed Effects } \\
\hline Intercept & $1,32(0.36)^{*}$ & $1,32(0.36)^{*}$ & $1,32(0.36)^{*}$ & $1,32(0.36)^{*}$ \\
\hline Gender & $0.58(0.16)^{*}$ & $0.58(0.16)^{*}$ & $0.58(0.16)^{*}$ & $0.58(0.16)^{*}$ \\
\hline Actor $(\mathrm{Q})$ & $0.01(0.01)^{* *}$ & $0.01(0.01)^{* *}$ & $0.01(0.01)^{* *}$ & $0.01(0.01)^{* *}$ \\
\hline Partner $(\mathrm{O})$ & $0.74(0.07)^{*}$ & $0.74(0.07)^{*}$ & $0.74(0.07)^{*}$ & $0.74(0.07)^{*}$ \\
\hline Dimension & $\mathrm{X}$ & - & - & - \\
\hline Dimension X Partner & $\mathrm{X}$ & - & - & - \\
\hline Being offered & - & - & - & - \\
\hline \multicolumn{5}{|l|}{ Random Effects } \\
\hline \multicolumn{5}{|l|}{ Level 1} \\
\hline Intercept & $1.04(0.10)$ & $1.04(0.10)$ & $1.04(0.10)$ & $1.04(0.10)$ \\
\hline \multicolumn{5}{|l|}{ Deviance intercept-only model 677.78} \\
\hline Deviance full model & 615.20 & 615.20 & 615.20 & 615.20 \\
\hline$\chi^{2}$ (as compared to empty model) & 62,58 & 62,58 & 62,58 & 62,58 \\
\hline
\end{tabular}

$N=214 . * p<0.001 ; * * p<0.01 ; * * * p<0.10$. Presented values are significant, or obligatory (when non-significant, indicated with NS) model variables. Non-significant values are omitted from the analyses, and indicated by dashes. Variables not in the analysis are indicated with an X.

An explanation for this difference can be that the effects from persuasion are stable over time and already reflected in the questionnaire data. That is, some individuals may be susceptible to persuasion from generally anyone, and usually there will be someone to play that role. The outcomes of modelling processes, on the other hand, might depend on the absolute drinking levels of those present in the drinking session and therefore lead to outcomes that were not reflected in the reported drinking.

Further, the sociometric status of peer group members does not predict variations between the amount of influence being exerted or received. This means that, even though adaptation in drinking takes place in groups, sociometric information does not add to the prediction regarding which members' drinking will most likely be a source of influence to others. In general, we have two possible explanations for these findings. The first is that sociometric status does make a difference, but no relations were found in this study. The second is that sociometric status does not make a difference concerning influence on drinking in groups.

Reasons for Lack of Findings concerning Sociometric Status: The Present Study

To start with the first explanation, one feature of this study may account for the absence of a differentiating role of sociometric status, namely that these measures are most often used in groups with younger people. Coie et al. (1982) showed that at a higher age, less variance in dependent variables can be accounted for by sociometric scores. This may imply that studying sociometric influences may be more successful in younger age groups.
Concerning the impact of age on influence processes as such, Berndt (1979) found that the peak concerning tendency to conform to peer antisocial behaviour lies around the age of 15. On the other hand, concerning alcohol use, Keefe (1994) found that the pressure to drink more increases with age, which might undo the effect of the decreasing tendency to conform. This suggestion is supported by studies of e.g. McLaughlin et al. (1985) and Urberg et al. (1997), who found no age differences in the amount of peer influence on alcohol use. Nevertheless, it is possible that apart from age differences concerning influence, sociometric status is more important in shaping drinking within groups in younger age groups.

A second reason for the lack of findings on the role of sociometric status would $\mathrm{be}^{4}$ that we applied sociometric measures on a continuous scale, instead of combining scores to classify people in groups (like Newcomb and Bukowski 1983). Combining continuous scores into twodimensional categories might have revealed certain combinations of sociometric scores that are predictive of social influence. On the other hand, Jiang and Cillessen (2005) reported that many scholars studying sociometric peer nominations have shifted to the use of continuous measures nowadays, and these measures allow for more exact measurements of (changes in) levels of the constructs assessed, in comparison with categorical measures.

\footnotetext{
${ }^{4}$ For completeness, we have tested variability in influence exerted and influenceability as a function of the sociometric status groups popular, neglected, rejected, controversial, and average. For none of these groups differences in effects were found.
} 
Third, the impact of people with a particular sociometric position may depend on the dyadic relation between the source of influence and the person being influenced. Different outcomes may, for example, be expected in the case where a popular person tries to persuade someone who does or does not like him or her (albeit that one cannot simply state that people who are not liked are of no importance in shaping behaviour); the dyadic evaluation of an influencer by a target of influence may be quite different from the total group's evaluation of this influencer.

A fourth reason why our sociometric measures did not explain influence may be that the nominations the participants were asked for were on a general level and not situation specific. Fink and Wild (1994) and Jiang and Cillessen (2005) suggested that it might be better to ask participants about which group members they would nominate in a certain situation or for a certain activity. In the present study this may have led to asking people, e.g., whom they were most willing to go out with, instead of whom they liked most; or who were the most dominant in persuading others to continue drinking rather than asking who were dominant in general.

Fifthly, we applied only one method of using sociometric information to study influence, whereas many other ways of using information of individuals' positions in a group are available, e.g. social network data (for an overview: Valente et al. 2004).

Finally, it is possible that influence in drinking resulting from sociometric position leads to different results than we expected from modelling or persuasion. They may be expressed in a manner that does not lead to convergence to behaviour in more or less the average of the peer group members' reports. For example, Dishion et al. (1999) found that friends may reinforce each other's deviant expressions, which may lead to overall elevated levels of antisocial behaviour in all youngsters.

\section{Reasons for Lack of Findings concerning Sociometric Status: No Actual Relation}

When looking more closely at the second explanation for the lack of findings related to sociometric status (i.e. that sociometric status does not make a difference concerning influence in drinking in our research groups), other explanations are possible. An example of why sociometric measures may be insufficient in predicting influence is that other processes play a role, together with sociometric status. For example, for group "political" reasons, certain individuals that may be well liked and even perceived as leaders in the group may not be followed when struggles concerning leadership occur. Also, group members may keep a balance when it comes to following others' behaviour, to maintain an equilibrium that each group member conceives as 'righteous. ${ }^{5}$ It may even be typical for friendship groups to not want to have strong leadership behaviour or to permit behaviour non-standard in the group; perhaps this even leads to the finding that attachment to friends has an effect on norm-breaking behaviour (Helsen et al. 1999). As friendships are formed on the basis of equality, leadership tendencies may even be a threat to the continuity of friendships.

Another possibility is that adaptation in drinking within groups takes place at a very basic level, and sociometric status and dyadic relations play a very limited role. The drinking levels of people present in a 'wet' context may be adopted, unrelated to these persons' sociometric status or relations existing between members in the group. For example, Overbeek et al. (2007) found that, in a bar lab setting, best friends' drinking did not predict individual drinking more than that of other group members. Bruun (1959) found that group members are likely to adopt the drinking of the heaviest drinker in the group. This may indicate a strong influence of people in the situation (irrespective of the type of interrelations they have), or possibly characteristics of the situation itself, on individual drinking. The findings of observational research in public drinking places of Van de Goor (1990), who found effects from gender composition of the group, group size and music volume on drinking levels, confirms the contextual specificity of drinking levels. This line of reasoning may be substantiated by findings of Van de Beek (2006) who found that, within a drinking situation, alcohol consumption will be modelled mainly from the people involved in the same subgroup and activity.

Group members, triggered by relatively simple causes, such as one person who starts to drink quickly, an overall tendency to celebrate, or positive expectancies or evaluations of alcohol use, may contaminate each other when together in a situation where alcohol is available. Therefore, we might understand young people's drinking in existing social groups in terms of social drifts leading to heavy drinking in one group and limited drinking in another, instead of influence processes affected by variations of group members' social roles.

\section{Limitations}

Apart from the explanations given for modest findings, some weaknesses of our study should be stressed. At first, we studied our participants' drinking for only one hour. Capturing longer drinking sessions may give more insight into what makes people quit drinking after a few drinks, or contrarily, what makes them binge.

Also, we claim to have captured already existing similarities between group members in the actor effects. It

\footnotetext{
${ }^{5}$ In that case, group leaders may only initiate drinking or ordering behaviour, instead of being dominant during a total drinking episode.
} 
is, however, possible that most of the influence took place in the past in these existing peer groups and therefore will not have been captured in this study. In that case, however, we would not have found significant partner effects, but we did. Consequently, our findings can be considered an addition to the literature of influence on current drinking and not one that allows claims on processes over time.

It can, as mentioned before, be questioned whether stronger influence processes in drinking can be expected in younger age groups. The young adults we studied may be at an age on which strong drinking habits already have developed and companions may not be making a large difference in the amounts of alcohol consumed. Also, for example, in the United States, different results may have been found, since drinking is illegal before the age of 21 , and drinking in bars is less common among young adults. To allow generalising findings, such differences should be taken into account.

\section{Conclusion}

Pointing back to the introduction of this paper in which it was stated that researchers' attention concerning best friends' influence on alcohol consumption is disproportionate compared to that for the peer group, we stress that the findings in the present study do not rule out that friends may be very influential concerning drinking patterns, for instance, by inviting each other to drinking occasions, and may remain influential within the situation, but possibly this may only be because of the time they spend together.

These findings may have relevance for the prevention of drinking in young adults. Besides the often-studied best friends, peer group members, or more basically the ones present in a drinking situation, may strongly affect individual alcohol consumption. This means that it may be appropriate to teach young people to resist influence overall, rather than teaching them skills to resist influence from leading figures. It may also be advisable to teach young persons to be aware of the potential automatism at which influence processes take place. Not the acts of persuasion, but the (more automatic) modelling of drinking is important in shaping the individual's drinking in a peer group. This knowledge may help to find prevention programmes for binge drinking, in any case for the part that is caused by the influence the youngsters may only partly or totally be unaware of.

Acknowledgments This study was supported by a fellowship of The Netherlands Organisation for Scientific Research to Rutger Engels. Address correspondence to: Sander M. Bot, Behavioural Science Institute, Radboud University Nijmegen, P.O. Box 9104, 6500 HE Nijmegen, The Netherlands.

\section{References}

Aitken, P. P. (1985). An observational study of young adults' drinking groups II. Drink purchasing procedures, group pressures and alcohol consumption by companions as predictors of alcohol consumption. Alcohol and Alcoholism, 20, 445-457.

Andrews, J. A., Tildesley, E., Hops, H., \& Li, F. (2002). The influence of peers on young adult substance use. Health Psychology, 21, 349-357.

Bartholew, B. D., Sher, K. J., \& Krull, J. L. (2003). Changes in heavy drinking over the third decade of life as a function of collegiate fraternity and sorority involvement: A prospective, multilevel analysis. Health Psychology, 22, 616-626.

Bauman, K. E., \& Ennett S. E. (1996). On the importance of peer influence for adolescent drug use: Commonly neglected considerations. Addiction, 91, 185-198.

Berndt (1979). Developmental changes in conformity to peers and parents. Developmental Psychology, 15, 608-616.

Bot, S. M., Engels, R. C. M. E., \& Knibbe, R. A. (2005a). The effects of alcohol expectancies on the drinking behaviour in peer groups: Observations in a naturalistic setting. Addiction, 100, 1270-1279.

Bot, S. M., Engels, R. C. M. E., Knibbe, R. A., \& Meeus, W. H. E. (2005b). Friend's drinking behaviour and adolescent alcohol consumption: The moderating role of friendship characteristics. Addictive Behaviors, 30(5), 929-947.

Brown, B. B., Clasen, D. R., \& Eicher, S. A. (1986). Perceptions of peer pressure, peer conformity dispositions, and self-reported behavior among adolescents. Developmental Psychology, 22, $521-530$.

Bruun, K. (1959). Drinking behaviour in small groups. Helsinki: Uudenmaan Kirjapaino.

Cairns, R., Xie, H., \& Leung, M. (1998). The popularity of friendship and the neglect of social networks: Toward a new balance. In Bukowski, W. M. \& Cillessen, A. H (Eds.), Sociometry then and now: Building on six decades of measuring children's experiences with the peer group. New directions for child development, No.80. San Francisco, CA: Jossey-Bass.

Chartrand, T. L., \& Jefferis, V. E. (2003). Consequences of automatic goal pursuit and the case of nonconsious mimicry. In Forgas, J. P., Williams, K. D., \& Von Hippel, W. (Eds), Social judgment: Implicit and explicit processes. New York, NY: Cambridge University Press.

Cialdini, R. B., \& Sagarin, B. J. (2005). Principles of interpersonal influence. In Brock, T. C. \& Green, M. C. (Eds), Persuasion: Psychological insights and perspectives (2nd ed). Thousand Oasks, CA: Sage.

Coie, J. D., Dodge, K. A., \& Coppotelli, H. (1982). Dimensions and types of social status: A cross-age perspective. Developmental Psychology, 18, 557-570.

Dishion, T. J., McCord, J., \& Poulin, F. (1999). When interventions harm: Peer groups and problem behavior. American Psychologist, 54, 755-764.

Engels, R. C. M. E., Bot, S. M., Van der Vorst, H, \& Granic, I. (2007). Smells like teen spirit: Gender differences in susceptibility to peer influences concerning alcohol consumption. (in press).

Engels, R. C. M. E., Knibbe, R. A., \& Drop, M. J. (1999). Visiting public drinking places: An explorative study in the functions of pub-going for late adolescents. Substance Use and Misuse, 34, 1261-1280.

Engels, R. C. M. E., Knibbe, R. A., Drop, M. J., \& De Haan, J. T. (1997). Homogeneity of smoking behavior in peer groups: Influence or selection? Health Education and Behavior, 24, 801-811. 
Ennett, S. T., \& Bauman, K. E. (1996). Adolescent social networks: School, demographic and longitudinal considerations. Journal of Adolescent Research, 11, 194-215.

Epstein, J. A., Griffin, K. W., \& Botvin, G. J. (2001). Risk taking and refusal assertiveness in a longitudinal model of alcohol use among inner-city adolescents. Prevention Science, 2, 193-200.

Fink, B., \& Wild, K. P. (1994). The impact of friendships on the development of leisure activities / Der Einfluss von Freundschaften auf die Entwicklung von Freizeitinteressen. German Journal of Educational Psychology, 8, 189-192.

Graham, J. W., Marks, G., \& Hansen, W. B. (1991). Social influence processes affecting adolescent substance use. Journal of Applied Psychology, 76, 291-298.

Hajema K. J., \& Knibbe, R. A. (1998). Changes in social roles as predictors of changes in drinking behaviour. Addiction, 93, $1717-1727$

Hartup, W. W. (1996). The company they keep: Friendships and their developmental significance. Child Development, 67, 1-13.

Helsen, M., Vollebergh, W., \& Meeus, W.H.J. (1999). Psychosocial problems in adolescence: The relation with attachment to parents and friends and identity / Psychosociale problemen in de adolescentie: De samenhang met hechting aan ouders en vrienden en identiteit. Nederlands Tijdschrift voor de Psychologie en haar Grensgebieden, 54, 256-275.

Jaccard, J., Blanton, H., \& Dodge, T. (2005). Peer influences on risk behavior: An analysis of the effects of a close friend. Developmental Psychology, 41, 135-147.

Jiang, X. L., \& Cillessen, A. H. N. (2005). Stability of continuous measures of sociometric status: A meta-analysis. Developmental Review, 25, 1-25.

Jost, G., Schatzle, E., Schenk, J., \& Wagner, E. (1985). Interaction with spouse compared to that with friends, coworkers, and neighbours / Interaktion mit dem (Ehe-)Partner im Vergleich zu der mit Freunden, Berufskollegen und Nachbarn. Zeitschrift für Experimentelle und Angewandte Psychologie, 32, 471-483.

Keefe, K. (1994). Perceptions of normative social pressure and attitudes toward alcohol use: Changes during adolescence. Journal of Studies on Alcohol, 55, 46-54.

Kenny, D. A., Mannetti, L., Pierro, A., Livi, S., \& Kashy, D. A. (2002). The statistical analysis of data from small groups. Journal of Personality and Social Psychology, 83, 126-137.

Knibbe, R. A., Oostveen, T., \& Van de Goor, I. (1991). Young people's alcohol consumption in public drinking places: Reasoned behaviour or related to the situation. British Journal of Addiction, 86, 1425-1433.

Latané, B. (1981). The psychology of social impact. American Psychologist, 36, 343-356.

Lease, A. M., Kennedy, C. A., \& Axelrod, J. L. (2002a). Children's social constructions of popularity. Social Development, 11, 87-109.

Lease, A. M., Musgrove, K. T., \& Axelrod, J. L. (2002b).Dimensions of social status in preadolescent peer groups: Likeability, perceived popularity, and social dominance. Social Development, $11,508-533$.

Maalsté, N. (2000). Ad fundum! Een blik in de gevarieerde drinkcultuur van het Nederlandse studentenleven (Ad fundum!
A gaze in the variated drinking culture of the Dutch students' life). Utrecht: Centrum voor Verslavingsonderzoek

Masten, A. S., Morison, P., \& Pellegrini, D. S. (1985). A revised class play method of peer assessment. Developmental Psychology, 21, 523-533.

Maxwell, K. A. (2001). Do friends matter? The role of peer influence on adolescent risk behavior. Dissertation abstracts international: Section B: The sciences and engineering Vol. 61 (10-B). US: Univ. Microfilms International.

McLaughlin, R. J., Baer, P. E., Burnside, M. A., \& Pokorny, A. D. (1985). Psychosocial correlates of alcohol use at two age levels during adolescence. Journal of Studies on Alcohol, 46, 212-218.

Moreno, J.L. (1934). Who shall survive. Nervous and Mental Disease Monograph 58. Washington DC.

Newcomb, A. F., \& Bukowski, W. M. (1983). Social impact and social preference as determinants of children's peer group status. Developmental Psychology, 19, 856-867.

Overbeek, G., Bot, S. M., Engels, R. C. M. E., Knibbe, R. A., \& Meeus, W. H. J. (2007). Where it's at: A longitudinal-observation study of context effects in peer influence on adolescents' alcohol use. Journal of Research on Adolescence. (in press)

Petraitis, J., Flay, B. R., \& Miller, T. Q. (1995). Reviewing theories of adolescent substance use: Organizing pieces in the puzzle. Psychological Bulletin, 117, 67-86.

Poelen, E. A. P., Engels, R. C. M. E., Van der Vorst, H., Scholte, R. H. J., \& Vermulst, A. A. (2007). Best friends and alcohol consumption in adolescence: A within family analysis. Drug and Alcohol Dependence, 88(2-3), 163-173.

Polansky, N, Lippitt, R., \& Redl, F. (1950a). An investigation of behavioural contagion in groups. Human Relations, 3, 319-348.

Polansky, N, Lippitt, R., \& Redl, F. (1950b). The use of nearsociometric data in research on group treatment processes. Sociometry, 13, 39-62.

Quigley, B. M., \& Collins, R. L. (1999). The modeling of alcohol consumption: A meta-analytic review. Journal of Studies on Alcohol, 60, 90-98.

Thissen-Pennings, M. C. E., \& Bendermacher, A. N. H. (2002). SOCSTAT: A program for sociometric status. Research Technische Ondersteuningsgroep (RTOG): Radboud University Nijmegen.

Urberg, K. A., Değirmencioğlu, S. M., \& Pilgrim, C. (1997). Close friend and group influence on adolescent cigarette smoking and alcohol use. Developmental Psychology, 33, 834-844.

Valente, T. W., Gallaher, P., \& Mouttapa, M. (2004). Using social networks to understand and prevent substance use: A transdisciplinary perspective. Substance Use and Misuse, 39, 16851712.

Van Daalen, G., Sanders, K., \& Willemsen, T. M. (2005). Sources of social support as predictors of health, psychological well-being and life satisfaction among Dutch male and female dual-earners. Women and Health, 41, 43-62.

Van de Beek, C. (2006). An application of the "social impact theory" in predicting young adult social drinking. Master's Thesis: Radboud University Nijmegen.

Van de Goor, L. A. M. (1990). Situational aspects of adolescent drinking behavior. Maastricht: Datawyse. 